\title{
DIABETIC FOOT ULCERS- OLD PROBLEMS, NEW TECHNOLOGIES
}

\author{
Anuj Mahajan'1, Tejinderpal Singh², Anju Bhagtana3 ${ }^{3}$ Aaina Malhotra 4
}

${ }^{1}$ Senior Resident, Department of Surgery, DMCH, Ludhiana, Punjab.

${ }^{3}$ Senior Resident, Department of Surgery, Fortis, Ludhiana, Punjab.

${ }^{2}$ Senior Resident, Department of General Surgery, DMC \& H, Ludhiana, Punjab.

${ }^{4} J u n i o r$ Resident, Department of Anaesthesia, DMC \& H, Ludhiana, Punjab.

\section{BACKGROUND}

ABSTRACT

The term diabetes mellitus is a metabolic disorder characterised by chronic hyperglycaemia with disturbances of carbohydrate, fat and protein metabolism resulting from defects in insulin secretion, action or both. Non-traumatic amputations mostly arise from diabetes mellitus and the chances are 15 - 46 times higher in diabetics. Further, foot complications are the most frequent reason for hospitalisation in patients with diabetes mellitus, accounting for up to $25 \%$ of all admissions.

Objective- To study the role of recombinant platelet derived growth factor in Wagner's grade 2 diabetic foot ulcer.

\section{MATERIALS AND METHODS}

In a prospective study on 50 patients, 25 patients were undertaken in the study group (Group A) and 25 patients in the control group (Group B). Study group received PDGF gel, while the control group received Betadine dressing. Patients were followed up after every two weeks up to eight weeks. Qualitative analysis was done according to the wound size, discharge type, discharge amount, cellulitis and granulation tissue.

\section{RESULTS}

The platelet derived growth factor plays a significant role in the treatment and outcome of diabetic foot ulcers. The end result was significant in all the measured parameters. 24 out of 25 patients in study group attained the end result as compared to 4 out of 25 patients in control group. In study group, there was significant reduction in the size of wound at $7^{\text {th }}$ week. In study group end point results were achieved in $96 \%$ cases, which included the complete closure of wound either by healing, suturing or skin grafting.

\section{CONCLUSION}

Recombinant platelet derived growth factor plays a significant role in treating diabetic foot ulcers.

\section{KEYWORDS}

Diabetic Foot, Platelet Derived Growth Factor, Healing.

HOW TO CITE THIS ARTICLE: Mahajan A, Singh T, Bhagtana A, et al. Diabetic foot ulcers- old problems, new technologies. J. Evolution Med. Dent. Sci. 2018;7(12):1493-1497, DOI: 10.14260/jemds/2018/338

\section{BACKGROUND}

The term diabetes mellitus is a metabolic disorder characterised by chronic hyperglycaemia with disturbances of carbohydrate, fat and protein metabolism resulting from defects in insulin secretion, action or both. ${ }^{1}$

Non-traumatic amputations mostly arise from diabetes mellitus and the chances are 15 - 46 times higher in diabetics.1,2,3 Further, foot complications are the most frequent reason for hospitalisation in patients with diabetes mellitus, accounting for up to $25 \%$ of all admissions.

Detection of Diabetes Mellitus in the early stages prevents amputations in $85 \%$ of cases. ${ }^{4}$ Almost $15 \%$ of the patients with diabetes develop lower limb ulceration during the course of treatment.5,6.7

The effect of motor neuropathy occurs early and leads to foot muscle atrophy with consequent development of the fat pad displacement, hammer toe and associated increase in plantar forefoot pressures. ${ }^{8}$ When an abnormal focus of pressure is added on with lack of protective sensation, this results in the development of callus, ulcer or blister. ${ }^{9}$

'Financial or Other Competing Interest': None.

Submission 12-01-2018, Peer Review 01-03-2018,

Acceptance 09-03-2018, Published 19-03-2018.

Corresponding Author:

Anju Bhagtana,

\#101 PG Hostel, DMC \& H, Ludhiana, Punjab.

E-mail: anju_bhagtana@rediffmail.com

DOI: $10.14260 /$ jemds $/ 2018 / 338$
Foot infections are amongst the most common lower extremity complications in the diabetic population with an incidence of 36.5 per thousand persons per year.

Ulcer is often classified on the basis of Wagner's system. ${ }^{2}$ Grade 1 ulcers are superficial ulcers involving the full thickness of skin. Grade 2 ulcers are deeper, penetrating the ligament and muscle, but not involving the bone. Grade 3 ulcers are with abscess formation and cellulitis often complicated with osteomyelitis. Grade 4 ulcers are with localised gangrene. Grade 5 are those involving the entire foot.

In the lower limb ulcer group, 33\% patients have history of diabetes mellitus. ${ }^{10}$ It should also be kept in mind that when a patient with diabetic foot ulcer suddenly develops pain in the ulcer, it may be indicative of worsening infection.

Platelet-derived growth factor (PDGF) stimulates DNA synthesis and chemotaxis of fibroblasts and smooth muscle cells. It also stimulates collagen, glycosaminoglycan and collagenase production by fibroblasts. PDGF-BB augmented wound breaking strength is $50 \%-70 \%$ over the first 3 weeks. In excision wounds, PDGF-BB accelerated time to closure by $30 \%$.

The two most important signals are platelet-derived growth factor (PDGF) and transforming growth factor-beta (TGF-ß). The PDGF initiates the chemotaxis of neutrophils, macrophages, smooth muscle cells and fibroblasts. In addition, it also stimulates the mitogenesis of the fibroblasts and smooth muscle cells. 
TGF- $ß$ adds another important signal for the initiation of the healing cascade by attracting macrophages and stimulates them to secrete additional cytokines including FGF (fibroblast growth factor), PDGF, TNF alpha (Tumour necrosis factor alpha) and IL-1 (interleukin-1). TGF- $§$ further enhance fibroblast and smooth muscle cell chemotaxis and modulate collagen and collagenase expression. These factors cause a vigorous response of the matrix producing cells to ensure a rapid deposition of new connective tissue at the injury site during the proliferative phase that follows the inflammatory phase. ${ }^{11}$

In addition, immuno-histochemically detectable PDGF receptors of both $\mathrm{a}$ and $\mathrm{b}$ type are localised on corneal endothelium of human corneas, the receptor being more abundant than the co-receptor.

PDGF-beta receptors, which bind only PDGF-BB and not other isoforms were found in normal skin and granulation tissue. This provided the molecular basis for treating human chronic wounds with exogenous rhPDGF-BB, 12 detection of platelet-derived growth factor (PDGF)-aa in actively healing human wounds treated with recombinant PDGF-bb and absence of PDGF in chronic non-healing wounds. ${ }^{13}$

Naturally occurring PDGF is composed of two peptide chains (A and $B$ ) held together by intermolecular disulfide bonds; both heterodimeric and homodimeric forms coexist. There are two subunit of PDGF receptor that has been identified and these are brought together in one of the isoforms of PDGF.

\section{MATERIALS AND METHODS}

It was a non-randomised controlled trial study conducted in Department of Surgery in Dayanand Medical College and Hospital, Ludhiana. Sample size was the total number of patients admitted from Jan. 2017 to June 2017. A total of 50 consecutive patients admitted to DMC and H Ludhiana from Jan. 2017 to June. 2017 fulfilling the inclusion criteria were entered into the study. The patients were allotted into two groups on the basis of even and odd. Study was conducted on 50 patients, out of which 25 patients (Group A) were enrolled in study group and 25 patients in control group (Group B). Group A received PDGF gel, while Group B received Betadine dressing. Patients were followed up after every two weeks up to eight weeks.

\section{Method of Data Collection Inclusion Criteria}

- Wagner's Grade I and II diabetic foot ulcers.

- Age 18 - 65 years.

- Ulcer size between $2 \mathrm{~cm}^{2}-50 \mathrm{~cm}^{2}$ in area measured according to the blotting paper area method.

- $\quad \mathrm{ABI}>0.75$.

\section{Method}

On the first day of treatment, the wound surface was cleaned with normal saline. In some patients, where there was lot of slough or some necrotic tissue present over the wound surface, surgical debridement was done before starting the treatment and pus culture and sensitivity test was done. In Group I, PDGF gel was applied. A dry sterilised gauze piece was placed over the dressing and covered with a bandage. The PDGF gel dressing was kept over the wound surface and changed daily. It was applied over the wound surface for a maximum period of 8 weeks. In Group II, dressing was done daily with betadine.

The Observations of the Treatment were recorded after Every Two Weeks. At each Inspection, the following Points were recorded-

1. Type of wound discharge, i.e. purulent/ seropurulent.

2. IL amount of wound discharge, whether increasing or decreasing.

3. Granulation tissue formation- as percentage of total surface area.

4. Changes in the size of wound as the largest transverse diameter and largest vertical diameter.

5. Presence of slough, if any- as percentage of total surface area.

6. Any cellulites in the surrounding area.

The data thus obtained was tabulated and analysed to evaluate the efficacy of platelet derived growth factor dressing.

\section{Outcome of Study}

Results were assessed on the basis of following criteria: Complete healing of the ulcer.

Split skin graft/ Suturing of the ulcer.

Surgical intervention of the involved non-healing ulcer.

Completion of 8 weeks of treatment.

\section{Statistical Analysis}

The Microsoft version SPSS 17. Chi-square test and student's ' $\mathrm{t}$ ' test was used to analyse the data.

\section{RESULTS}

At the end of 8 weeks, the results that were obtained were as follows-

\section{Type of the Discharge}

Initially in Group A, all patients had discharging ulcer. One patient had purulent discharge, 10 patients had serous and14 patients seropurulent. In Group B all the patients had discharging wound with 4 patients purulent, 6 patients serous and 15 patients seropurulent wound.

It was observed that by the end of eight weeks, Group A had only 1 patient left with serous discharge. Patients with healed wounds were 24 (96\%) (P value- 0.001). However, in Group B 12 patients had healed wound, 3 patients had seropurulent discharge, 10 patients had serous discharge by the end of $8^{\text {th }}$ week.

\section{Discharge Amount}

Initially, all patients in both the groups had discharging ulcers. In the $2^{\text {nd }}$ week 17 patients in Group A showed a decreasing trend, whereas 10 patients in Group B had similar trends. In Group A, 2 patients were resistant to the treatment in comparison to the 11 patients in Group B. In the $4^{\text {th }}$ week, it was observed that $19(76 \%)$ in Group A had decreasing trend and $15(60 \%)$ patients had decreasing trend in Group B. In Group B, 8 (32\%) patients were resistant to the treatment. In the $6^{\text {th }}$ week, $15(60 \%)$ patients from Group B were showing decrease in the discharge and in Group A 10 (40\%) patients showed a decrease in the discharge. 10 patients from Group A had achieved the end result at the end 
of $6^{\text {th }}$ week. In Group B at the $6^{\text {th }}$ week, only 5 patients achieved the end point.

By the $8^{\text {th }}$ week, 24 (96\%) patients in Group A had healed wound. In Group B, 12 (48\%) had healed wound.

\section{Granulation Tissue}

Initially, 13 patients in Group A and 10 patients in Group B had granulation tissue. In the $2^{\text {nd }}$ week, 22 (88\%) patients from Group A had an increase in the surface area covered by granulation tissue, whereas 12 (48\%) patients from Group B showed such trend. At this point of time, resistance to treatment was shown by 3 patients in Group A and 10 from Group B. In the $4^{\text {th }}$ week all patients in Group A continued to show an increasing trend, whereas in Group B 16 (64\%) patients showed similar trends. At the end of fourth week, no patient in Group A and 7 patients in Group B showed resistance to treatment. In the sixth week $16(64 \%)$ patients in Group A showed an increase and so did 16 (64\%) patients in Group B. One patient showed decrease in the surface area covered with granulation tissue in Group B.

In $8^{\text {th }}$ week, only one patient in Group A had increase in the surface area covered by granulation tissue with 12 patients showing a similar trend in Group B. Resistant ulcers were seen in 4 patients in Group B patients as compared to no patient in Group A. Complete wound closure occurred in 24 out of 25 patients (96\%) in Group A as compared to the Group B, where only 12 (48\%) cases fully recovered.

\section{Slough}

Initially, 13 patients in Group A and 18 patients in Group B had slough in the wound. By the end of $8^{\text {th }}$ week, no patient from Group A had slough as compared to 12 patients from Group B.

\section{Cellulitis}

Initially, 16 patients in Group A and 22 patients in Group B had surrounding cellulitis. At $8^{\text {th }}$ week, no patient from Group A had cellulitis; however, 4 patients from Group B showed surrounding cellulitis ( $\mathrm{P}$ value $<0.001)$.

\section{Size}

Mean size at the beginning of the study in Group A was $12.240 \mathrm{~cm}^{2}$, while in Group B it was $17.540 \mathrm{~cm}^{2}$. In the 2nd week 22 (88\%) patients from Group A showed a decreasing trend, whereas $12(44 \%)$ patients from Group B showed a similar trend $(p=0.002)$. Three patients $(12 \%)$ in Group A were resistant to the treatment as compared to 14 patients (56\%) from Group B (P value= 0.001). In the $4^{\text {th }}$ week 22 patients (88\%) had a decreasing trend in Group A as compared to 13 patients $(56 \%)$ in group B. 2 patients from Group A and 11 patients from Group B were resistant to the treatment $(\mathrm{P}$ value $=0.014)$. In the $6^{\text {th }}$ week, 15 patients (60\%) from Group A and 16 patients (64\%) from Group B showed decreasing trend. No patient from group $A$ and 7 patients from Group B were resistant to the treatment. ( $P$ value $=0.002$ ). At 8 weeks, 3 patients from Group B were resistant to the treatment as compared to no patient from Group A. Decreasing trend was seen in 1 patient from Group A and in 13 patients of Group B. About 24 of the 25 patients in Group A reached the end point result ( $\mathrm{P}$ value $<0.001$ ). In Group A 4 patients underwent SSG, 19 patients had completely healed ulcers, 1 patient had their wound sutured and 1 patient had incompletely healed wound.

In Group B 1 patient underwent SSG, 1 patient had completely healed ulcer, 4 patients required debridement, 18 patients had incomplete healing and 1 patient got his wound sutured (Table 1).

\begin{tabular}{|c|c|c|}
\hline $\begin{array}{c}\text { Time in } \\
\text { Weeks }\end{array}$ & $\begin{array}{c}\text { No. of Patients } \\
\text { Reaching End Point } \\
\text { Group A }\end{array}$ & $\begin{array}{c}\text { Number of Patients } \\
\text { Reaching End Point } \\
\text { Group B }\end{array}$ \\
\hline 3 & 1 & 1 \\
\hline 4 & 0 & 0 \\
\hline 5 & 3 & 0 \\
\hline 6 & 14 & 1 \\
\hline 7 & 2 & 3 \\
\hline 8 & \multicolumn{2}{|c|}{} \\
\hline \multicolumn{2}{|c|}{ Table 1. Comparison of Time Taken to reach End Point } \\
\hline
\end{tabular}

\section{DISCUSSION}

Diabetes Mellitus is one of the leading causes of neurotrophic ulcers of foot. Ulcers heal slowly because of repeated trauma and weight bearing, peripheral neuropathy from underlying diabetes mellitus and in many cases, there is reduced peripheral arterial vascularity. ${ }^{14}$ For the successful treatment of the diabetic neuropathic ulcer, proper selection of the patient with diabetes is a must. Ankle-brachial index is not satisfactory for determining the perfusion of the ulcerated region, as calcified vessels are poorly compressible. Doppler derived arterial flow is falsely elevated. In this study, we have assessed the ability of a single growth factor in the treatment of diabetic foot ulcers. Our results in this study have shown a significant improvement of diabetic wounds in patients treated with rhPDGF-BB.

It was reported that simian sarcoma virus can transform PDGF-responsive cell type and other cells like human fibroblast cells to grow in soft agar and in focus formation of monolayer. ${ }^{15}$ PDGF can bind to receptors on their own surface, whereas other cells do not have the PDGF receptor but secrete PDGF that binds to receptors on connective cells in the tumour environment. There are chances that PDGF may be involved in tumour proliferation theoretically. 16

Few reports are available in literature for the use PDGF in chronic non-healing diabetic foot ulcer. Previously, the study was done using the platelet derived growth factor extract which was not a single growth factor. It was mixture of the growth factor like tissue growth factor, EGF and platelet derived growth factor.

Buchberger et al (2011) studied the effectiveness and efficacy of various agents used in the treatment of diabetic foot ulcer. These agents included becaplermin, rhEGF, bFGF and metabolically active skin grafts (Dermagraft and Apligraf) with the standard wound care (SWC) alone or extracellular wound matrix. Authors analysed 25 different studies comparing these agents. The study duration varied from 12 to 20 weeks. A total of 382 patients were treated with the becaplermin, Dermagraft and the Apligraf resulted in higher incidence of complete wound healing and it also shortened the complete healing time. There was statistical significance in the study. ${ }^{17}$

In another study done by American Society of plastic surgeons, there is evidence that the recombinant human platelet derived growth factor- BB may promote healing of 
chronic diabetic neurotrophic foot ulcers when combined with basic preferred practices in wound care. ${ }^{18}$

The study by wound healing society, which provides guidelines for the treatment of diabetic ulcers suggests that platelet derived growth factor is effective in treating these neurotrophic ulcers. According to guidelines of Wound Healing Society, the use of growth factor therapy should be considered for the neurotrophic ulcers and non-responsive pressure ulcers in the initial stage of pressure ulcers before giving any surgical therapy. Further, according to Wound Healing Society guidelines the use of platelet derived growth factor in the venous ulcers has been reported in a very few studies, so the clear-cut usefulness of platelet derived growth factor in the venous ulcer is doubtful. ${ }^{19}$

Saad Setta et al (2011) conducted the study on 24 patients using platelet rich plasma and platelet poor plasma, each group having equal number of patients. The results showed that the platelet rich plasma had a significant result in the treatment of diabetic foot ulcers that were of chronic pathology. 20

Driver et al (2006) conducted a prospective, randomised controlled, blind, multicentric study on 72 patients with diabetic foot ulcers who were treated with autologous platelet rich plasma or control saline gel. Study showed $81.3 \%$ healing rates in group using platelet rich plasma as compared to the control group, which had success rate of 42.1\%.21 Villela and Santos (2010) reviewed the various studies in accordance to the Cochrane collaboration with studies published until 2008. About 18 studies on ulcers of diabetic aetiology were selected, out of which 17 were randomised controlled trials. The result of the meta-analysis showed that the platelet rich plasma favours the healing process in these diabetic ulcers. This systematic review proves that there is scientific evidence, which is in favour of use of platelet derived growth factor in the treatment of diabetic foot ulcers. ${ }^{22}$ Cochrane review, Martinez-Zapata et al (2012) reviewed the nine randomised controlled trials including 325 participants and proved the usefulness of platelet rich plasma that promotes the healing of chronic wounds. ${ }^{23}$

Frykberg et al (2010) conducted the prospective studies on the use of platelet derived growth factor in the initial wound healing pathway. Utilising the trajectory of chronic, non-healing wounds of various aetiologies, the study proved that the application of this factor results in the reversal of non-healing trends in chronic wound. Out of all wound aetiologies, $97 \%$ of the wounds improved. ${ }^{24}$

De Leon et al (2011) conducted a large, multicentre study on 285 patients on the use of platelet derived factors on all kinds of wounds. The aetiologies of wound included diabetic, pressure, venous and traumatic. Results were determined on the basis of clinical improvement of the wound. A positive response occurred in $96.5 \%$ of the wounds within 2.2 weeks. There was reduction in the surface area of ulcer upto $47.5 \%$ in almost $86 \%$ of patients in 2.8 weeks of time. Thus, the study concluded that the use of platelet rich plasma helped in complete healing of wound. ${ }^{25}$

\section{CONCLUSION}

Platelet derived growth factor plays a significant role in the treatment and outcome of diabetic foot ulcers. In this study, the group on platelet derived growth factor has end point results achieved in $96 \%$ cases, that is complete closure either by healing, suturing or skin grafting.

\section{REFERENCES}

[1] WHO. Classification of Diabetes mellitus 2003.

[2] Wagner FW. The dysvascular foot: a system for the diagnosis and treatment. Foot Ankle 1981;2(2):64122.

[3] Smith DM, Weinberger M, Katz BP. A controlled trial to increase office visits and reduce hospitalization of diabetic patients. J General Int Med 1987;2(4):232-8.

[4] Armstrong DG, Lipsky BA. Advances in the treatment of diabetic foot infections. Diabetes Technol Ther 2004;6(2):167-77.

[5] Steed DL. Clinical evaluation of recombinant human platelet-derived growth factor in the treatment of lower extremity diabetic ulcer. J Vascular Surgery 1995;21(1):71-8.

[6] Brown GL, Nanney LB, Griffen J, et al. Enhancement of wound healing by topical treatment with epidermal growth factor. N Engl J Med 1989;321(2):76-9.

[7] Mason J, O'Keeffe C, Hutchinson A, et al. A systemic review of foot ulcer in patients with type 2 diabetes mellitus. II: treatment. Diabet Med 1999;16(11):889909.

[8] Armstrong DG, Stacpoole-Shea S, Nguyen H, et al. Lengthening of the Achillies in the diabetic foot who are at high risk of ulceration of the foot. J Bone Joint Surg Am 1999;81(4):535-8.

[9] Brand PW. Repetitive stress I the development of diabetic foot ulcers. In: Levin ME, Davidson JK. eds. The diabetic foot. $4^{\text {th }}$ edn. St. Louis: Mosby 1988: p. 8390.

[10] Veves A, Manes C, Murray HJ, et al. Painful neuropathy and foot ulceration in diabetic patients. Diabetes Care 1993;16(8):1187-9.

[11] Diegelmann RF, Evans MC. Wound healing: an overview of acute, fibrotic and delayed healing. Front Biosci 2004;9:283-9.

[12] Pierce GF, Tarpley JE, Tseng J, et al. Detection of platelet-derived growth factor (PDGF)-AA in actively healing human wounds treated with recombinant PDGF-BB and absence of PDGF in chronic non-healing wounds. J Clin Invest 1995;96(3):1336-50.

[13] Pierce GF, Tarpley JE, Tseng J, et al. Department of experimental pathology. Thousand Oaks, California 91320, USA: Amgen Inc., 1989;158(4):345-0.

[14] Wieman TJ, Griffiths GD, Polk HC. Management of diabetic mid foot ulcers. Ann Surg 1992;215(6):62732.

[15] Levin ME. Diabetic foot ulcers: pathogenesis and management. J Enterostomal Ther Nurs 1993;20(5):191-8.

[16] Ross R. Peptide regulatory factors: platelet derived growth factor. Lancet I 1989: p. 1179-82.

[17] Buchberger B, Follmann M, Freyer D, et al. The evidence for the use of growth factors and active skin substitutes for the treatment of non-infected diabetic foot ulcers (DFU): a health technology assessment (HTA). Exp Clin Endocrinol Diabetes 2011;119(8):472-9. 
[18] National Institute for Health and Clinical Excellence (NICE). Diabetic foot problems: inpatient management of diabetic foot problems. Clinical guideline (CG119) Feb 1, 2012.

[19] Steed DL, Attinger C, Colaizzi T, et al. Guidelines for the treatment of diabetic ulcers. Wound Repair Regen 2006;14(6):680-92.

[20] Saad Setta H, Elshahat A, Elsherbiny K, et al. Plateletrich plasma versus platelet-poor plasma in the management of chronic diabetic foot ulcers: a comparative study. Int Wound J 2011;8(3):307-12.

[21] Driver VR, Hanft J, Fylling CP, et al. A prospective, randomized, controlled trial of autologous plateletrich plasma gel for the treatment of diabetic foot ulcers. Ostomy Wound Manage 2006;52(6):68-70, 72, 74.
[22] Villela DL, Santos VL. Evidence on the use of plateletrich plasma for diabetic ulcer: a systematic review. Growth Factors 2010;28(2):111-6.

[23] Martinez-Zapata MJ, Martí-Carvajal AJ, Solà I, et al. Autologous platelet-rich plasma for treating chronic wounds. Cochrane Database Syst Rev 2012;10:CD006899.

[24] Frykberg RG, Driver VR, Carman D, et al. Chronic wounds treated with a physiologically relevant concentration of platelet-rich plasma gel: a prospective case series. Ostomy Wound Manage 2010;56(6):36-44.

[25] De Leon JM, Driver VR, Fylling CP, et al. The clinical relevance of treating chronic wounds with an enhanced near-physiological concentration of plateletrich plasma gel. Adv Skin Wound Care 2011;24(8):357-68. 